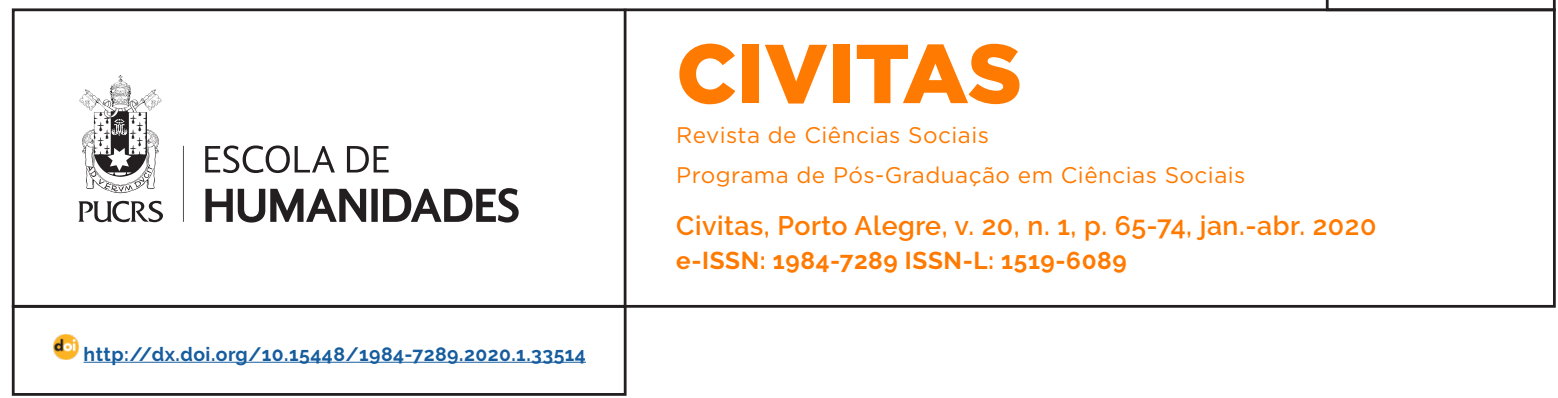

ARTIGOS / ARTICLES

\title{
Transformaciones en la legislación familiar y en la moralidad de los grupos familiares de la Ciudad de México
}

\author{
Transformações na legislação familiar e na moralidade dos \\ grupos familiares da Cidade do México \\ Transformations in family legislation and morality of family groups in Mexico City
}

\author{
María Carolina Agoff ${ }^{1}$ \\ orcid.org/0000-0002-3809- \\ $460 X$ \\ agoff@correo.crim.unam.mx

\section{Claudia Esthela \\ Espinoza $\mathrm{Cid}^{2}$ \\ orcid.org/0000-0002-0045-178X} \\ espinozaclaudia@hotmail.com
}

Recebido em: 06 mar. 2019 Aprovado em: 02 set. 2019 Publicado em: 25 mai. 2020
Resumen: En México las familias han sufrido considerables transformaciones de carácter estructural y sociocultural y es posible observar que ya no se rigen por un canon normativo único. Este artículo se propone analizar si, a la luz de los cambios tanto en las prácticas como en la legislación de familia y de género, han habido modificaciones también en los valores y las normas de convivencia familiar y en el modo en que éstos se legitiman moralmente en la Ciudad de México. En un sentido más amplio, se busca analizar la moralidad de los intercambios de grupos familiares residentes en la señalada ciudad. Los hallazgos que se presentan acá provienen de una investigación cualitativa en la que se llevaron a cabo 10 grupos de discusión con mujeres de la capital de los Estados Unidos Mexicanos sobre convivencia, distribución de tareas y cuidado en sus familias. Los resultados sugieren que los nuevos estándares de justicia social y un contexto de ampliación de derechos para mujeres, adultos mayores y niños favorecen el surgimiento de una nueva moralidad en las familias, muy diferente al modelo heteronormativo de familia.

Palabras clave: Derecho. Grupos familiares. Moralidad.

Resumo: No México as familias têm sofrido consideráveis transformações de caráter estrutural e sociocultural. É possivel observar que já não são mais regidas por um cânone normativo único. Este artigo propõe-se a analisar se, à luz das mudanças tanto nas práticas como na legislação de família e gênero, tIn: havido modificações também nos valores e nas normas de convivência familiar e no modo como estas se legitimam na Cidade do México. Num sentido mais amplo, busca-se analisar a moralidade das mudanças nos grupos familiares residentes na referida cidade. Os achados que apresentamos resultam de uma pesquisa qualitativa para a qual realizou-se dez grupos de discussão com mulheres da capital dos Estados Unidos Mexicanos sobre convivência, distribuição de tarefas e cuidado In: suas familias. Os resultados sugerln: que os novos padrões de justiça social e um contexto de ampliação dos direitos de mulheres, adultos e crianças favorecln: o surgimento de uma nova moralidade nas famílias, muito diferente do modelo heteronormativo de família. Palavras-chave: Direito. Grupos familiares. Moralidade.

Abstract: In Mexico families have suffered considerable transformations of a structural and cultural character and it is possible to observe they are not ruled anymore by an exclusive normative canon. In this article it is proposed to analyze if, in the light of changes in the practices as well in family and gender legislation, the values and norms of cohabitation/coexistence and the way they are morally validated have also changed. We intend to analyze the morality of the family exchanges. Findings presented here come from a qualitative research in which were conducted 10 focus groups with women from Mexico City on the issue of cohabitation/coexistence, distribution of chores and care in their families. The results suggest that new standards of social justice and a growing context of women, elderly and children's rights favour the emergence of a new morality in the families, far different from the heteronormative model of family.

Keywords: Law. Family arrangements. Morality. 


\section{Introducción}

El panorama de las familias en México está cambiando por muchas y diferentes razones. Algunos cambios derivan de transformaciones históricas de carácter estructural, económico y político tales como la desaceleración demográfica de los 60's fruto de las políticas de planificación familiar, ${ }^{3}$ la desindustrialización a partir de esa década y el fuerte desempleo, 4 la informalización del trabajo, la movilidad social gracias a la mayor escolarización de hijos e hijas, la incorporación masiva de las mujeres al mercado de trabajo, ${ }^{5}$ un aumento en los hogares con jefatura femenina, la creciente y sostenida migración -en su mayoría de hombres- hacia los Estados Unidos de Norteamérica, entre otros.

Se suman a ello las modificaciones socioculturales asociadas con la pluralización de formas de vida que propician una diversidad familiar que se aparta cada vez más de los dictados de un canon normativo único. Es posible observar valores hegemónicos que poco a poco se desdibujan y la emergencia de una nueva y variada gama de valores en el ámbito familiar.

La literatura académica en México constata un mosaico plural de arreglos familiares (López y Salles 2000; Ariza y Oliveira 2004; García y Oliveira 2006; Esteinou 2008; Cuevas 2010; Lerner y Melgar 2010; Rojas 2012), o de tramas familiares contemporáneas (Rabell y Andrea 2009) diferentes a la imagen clásica de familia nuclear y/o extendida. Hasta el 2000 se observaba que los cambios en las prácticas no se habian visto reflejados de manera análoga en transformaciones de la subjetividad y de los vínculos (Oliveira 2000).

Estas transformaciones en las familias han supuesto modificaciones en los roles familiares tradicionales, en la estructura de poder (clásicamente conocida como patriarcado), en la composición (en sus miembros o integrantes), lo mismo que en el tipo de intercambios y vínculos. ${ }^{6}$

Junto a los cambios sociodemográficos y económicos se pueden observar profundos cambios legislativos a nivel constitucional, penal, civil y familiar. Se han reformado algunas disposiciones constitucionales que trazaron las primeras directrices sobre la igualdad juridica entre mujeres y hombres (Torres 2009, 42). Asimismo, se modificaron legislaciones familiares en la mayoría de los estados para considerar la violencia de pareja como una causal de divorcio, se tipificó la violación conyugal como delito y se despenalizó el aborto en varias entidades, y hace una década se estableció la posibilidad de interrupción legal del embarazo en la Ciudad de México? También se han creado normas, políticas públicas y dependencias federales, estatales y municipales ${ }^{8}$ para el combate de la violencia de género. ${ }^{9}$

\section{Legislación familiar y de género y justicia en las relaciones familiares}

En las últimas dos décadas han producido cambios legislativos sobre cuestiones de género

\footnotetext{
Desde 1970 a 2005 ha descendido la fecundidad de forma acelerada, pasó de 6.8 a 2.1 hijos por mujer.

4 Según Ivonne Szasz (1994), la crisis económica que afectó al empleo y al ingreso de los varones favoreció el aumento de las jefaturas femeninas a partir de los '80, pero los efectos positivos en relación a la autonomía de las mujeres y mayor igualdad de género todavía son controvertidos. De la conjunción de los condicionamientos de género para la participación femenina, las mayores necesidades económicas de los hogares y la búsqueda de mano de obra barata y flexible del capital, favorece el surgimiento de un mercado específico y definido para la mano de obra femenina (Szasz 1994, 26).

5 Como ha sucedido en otras partes del mundo, en México las mujeres han tenido un aumento sin precedente en el ámbito laboral, pasando del 19\% en 1970 al 40.6\% en 2014 (Inegi 2014).

6 Según Arriagada (2009), los tres ámbitos en los que estas transformaciones familiares resultan más evidentes son el ejercicio de la sexualidad, la procreación y la convivencia familiar.

7 En la Ciudad de México se han realizado modificaciones legislativas que se orientan al reconocimiento de esta pluralidad de arreglos familiares y de la equidad de género. Algunos ejemplos son la posibilidad de los matrimonios igualitarios, de interrupción legal del embarazo o de fertilización asistida, y que han sido recogidas en la legislación capitalina antes que en la mayoría de las entidades federativas. 8 Por supuesto, es posible observar que los ritmos en los cambios legislativos que reconocen la pluralidad de los arreglos familiares varían en las regiones de México. Si se toma como ejemplo la cuestión del aborto pueden encontrarse algunas entidades que hasta ahora sólo lo han despenalizado (es decir, si bien no lo criminalizan en ciertas circunstancias, no permiten el acceso a un aborto libre y seguro), mientras que la capital de la República se admite la interrupción legal del embarazo.

9 Al menos en la última década se han adoptado en este país varias leyes y políticas públicas orientadas a las mujeres. Con la intención de cerrar la brecha de desigualdad con los hombres, se incorporó la perspectiva de género como eje transversal en las políticas públicas. También se expidieron leyes sobre igualdad, paridad política y contra la violencia, en este marco se han creado instancias de las mujeres y unidades de género en las dependencias públicas de los tres órdenes (federal, estatal y municipal).
} 
y de familia en México. Sin embargo, no hace mucho, todavía era posible encontrar en el derecho clásico (dominante) diversas teorías que concebian al matrimonio como unitas carnis Iteoria medieval sobre el establecimiento de una vida fraternal o carnal común (Bestard 1998 apud Solana 1998)] y que servían de justificación para la subordinación de la mujer hacia el marido ${ }^{10}$ (Chávez 1993), visiones como éstas solian hacerse eco en la legislación en México hasta antes de las reformas.

El derecho debe ser un espacio de lucha para el feminismo (Smart 2000), un lugar en el que discutir -en forma crítica- acerca de los significados del género. Por ello, el feminismo cuestionará los métodos, las metodologias y las bases teóricas de la ciencia del derecho, y se interesará por mostrar que sus rasgos básicos son el sexismo, la misoginia y el androcentrismo. La incursión de las teóricas feministas alertará también del uso discursivo del derecho para la dominación y el control sobre los cuerpos de las mujeres, y del papel clave que este sometimiento ha tenido en la situación subordinada de la mitad del colectivo humano (Galicia 2016, 125); en sintesis criticará la visión funcionalista sobre la familia y las esferas separadas. ${ }^{11}$

Gracias a la teoría de género se abrieron paso nuevas visiones que postulan la igualdad juridica de la mujer y del varón. El feminismo criticó en especial la visión funcionalista sobre la familia como una esfera de interacción separada con intereses internos y roles especializados; a la vez que contribuyó con la idea de la intersección multi-institucional entre las familias, los estados y los mercados, que son generizados a través de dinámicas específicas temporales y locales. Aportó de igual manera la noción de que el género es una inequidad estructural vinculada con otras desigualdades como raza, clase, edad u orientación sexual (Marx Ferree 2010).

En este orden de ideas, las relaciones familiares se consideran el paradigma de las relaciones morales par excellence (Maclntyre 1981). Esto tiene un aspecto crucial y diferente a otro tipo de relaciones, por lo que toca a las consecuencias para justificar la acción moral: los puntos de referencia no son principios universales, sino los lazos morales de una comunidad particular (la familia) irremplazable como tal. Con ello se evidencia el status que tiene la moral en las relaciones personales, en especial, en las relaciones afectivas (familia, amor, amistad). A esto llamaron la atención, la crítica feminista y la ética del cuidado, posturas teóricas que pusieron a las relaciones personales -incluidas las familiares- en el centro de la filosofía moral (Gilligan 1982; Held 1993).

\section{Objetivos y metodología}

A través de este texto se analizan las transformaciones en las formas y los arreglos normativos de convivencia que adoptan diversos grupos familiares en la Ciudad de México desde una perspectiva de género, ello en un contexto reciente de cambios tanto en las prácticas como en la legislación familiar y de género. Bajo la premisa de que la familia es una institución generizada se indaga en la moralidad de los intercambios que caracteriza diversos arreglos familiares y el modo en que éstos se legitiman moralmente, a partir de la mirada de mujeres residentes en la capital de la República Mexicana.12

Todo esto se asocia con el surgimiento de una legislación (se enfatiza aqui la de familia y de género), cuya aspiración (al menos formal) es ser más dinámica e incluyente. Legislación que, acorde con tratados internacionales sobre

\footnotetext{
10 Esta teoría o conjunto de postulados fueron rebatidos por Wollstonecraft (2005) ya desde 1792.

Desde luego que la legislación penal, civil y de familia continúan siendo celosamente resguardadas por los sectores conservadores de la sociedad en diversas regiones de México. Al menos en este sentido pueden leerse las demoras en reformas como la del matrimonio igualitario. El retraso de estos cambios quizá se produzca para evitar la incorporación de un concepto de matrimonio que postule la universalidad de los contrayentes y que esto le reste centralidad a la pareja heterosexual. Y esto ha sucedido pese a que tales retardos legislativos contradicen las recomendaciones de organismos internacionales y los criterios de la Suprema Corte de Justicia de la Nación en México.

12 Aquí se recupera una definición amplia de familia a partir de las ideas de Iris Young (1997). Las personas conforman una familia cuando se entienden a sí mismos como una relación más o menos permanente, viven en un hogar en el sentido de que comparten recursos y cuando se definen a si mismos como familia. Además de este reconocimiento se incluyen las obligaciones y los cuidados que se consideran pertinentes y legítimos para ser considerados parte de esta unidad.
} 
derechos humanos, se va a apartar de manera gradual de los requisitos de la heterosexualidad y de la procreación como principios fundantes de los arreglos familiares. Se trata de diversas normas jurídicas que transitan hacia el reconocimiento de los diversos tipos de familias -cada vez másbasados en la afectividad y la convivencia.

Pero los nuevos ordenamientos legales no sólo constituyen el contexto donde se inserta la moralidad en los intercambios de grupos familiares; derecho y moralidad comparten una influencia reciproca, por lo que resulta de particular interés explorar sus vínculos. ${ }^{13}$ Según Torres (2009), las leyes se originan en realidades históricas específicas y conllevan la visión moral de la sociedad que las crea; mediante ellas se definen principios, valores y comportamientos percibidos como buenos y útiles (2009, 43). Si bien, entre moral y derecho puede percibirse una influencia mutua, también se dan casos en que las nuevas moralidades emergen precisamente a raíz de los cambios jurídicos. ${ }^{14}$

Es por las particularidades de la relación entre moral y derecho que en el presente artículo se procura analizar las transformaciones en la moralidad de intercambios en grupos familiares (cómo se construye, cómo se legitima y cómo se justifican moralmente los vínculos) ${ }^{15}$ de la Ciudad de México, lo que acontece en el marco de profundos cambios en la institución social de la familia y en la legislación sobre género y familias. Con base en el supuesto de que las variaciones pueden obedecer a la posición social y pertenencia generacional; y en consonancia con el análisis de la interseccionalidad, se toman en cuenta las diferentes orientaciones valorativas y prácticas, según la pertenencia generacional o grupo etario así como la de clase o de posición social.

Los hallazgos que se presentan forman parte de una investigación de naturaleza cualitativa con grupos de discusión con mujeres que desempeñan algún trabajo extra doméstico en la Ciudad de México ( $\mathrm{N}=112) .{ }^{16}$ El objetivo fue analizar en las transformaciones en las normas y en los valores que orientan (explícita o implícitamente) los intercambios materiales y afectivos de diversos grupos familiares que residen en la mencionada ciudad. A este respecto, cabe considerar que los grupos familiares imponen sus propias reglas de convivencia, algunas se establecen de manera explícita, otras son comunes a toda la sociedad, algunas se dirigen a ciertos grupos y otras únicamente se hacen evidentes frente a situaciones problemáticas.

Con el propósito de analizar las normas, los valores y la acción creativa que constituyen la vida familiar en los grupos en estudio, se desarrollaron diversos elementos de indagación y producción de datos. De este modo, los grupos de discusión (Weller y Pfaff 2010) se consideran un dispositivo apropiado para indagar sobre sus valores en disputa, sus normas y sus valores tácitos, elementos que en la discusión se hicieron evidentes. Desde un punto de vista teórico-metodológico, se trata de un dispositivo de producción de datos que recoge el intercambio comunicacional de un grupo y la dinámica de interacción grupal que se generan a partir de los temas que introduce el moderador, pero también sobre aquellos que emergen de modo espontáneo.

Los criterios de selección del universo poblacional para el muestreo teórico en este artículo fueron dos: por un lado, la posición social: 1) sectores medios (secretarias del sector privado, funcionarias del sector público y amas de casa), con secundaria y preparatoria; y 2) bajos (personal femenino de intendencia, obreras y comerciantes informales), con primaria. Por otro lado, la pertenencia generacional fue otro criterio selectivo que se empleó en el

\footnotetext{
13 Por supuesto el derecho no se agota en las leyes (Torres 2009, 42); sin embargo, para los propósitos de este texto el derecho remite a los cambios legislativos en materia familiar en la ciudad de estudio.

14 Un ejemplo de esto seria la violencia de pareja, en donde la legislación es la que parece promover un cambio de mentalidades, asi también hay otros casos en que el derecho "se adelanta" a los cambios en las costumbres.

15 La moralidad en su acepción filosófica-política y social alude a deberes y derechos específicos, así como a los problemas derivados de la aplicación de principios éticos generales, en este caso en el ámbito de las relaciones familiares (Honneth y Roessler 2008).

16 Estos hallazgos forman parte de una investigación amplia sobre género, familia, trabajo y subjetividad femenina a cargo de Cristina Herrera (Piem-Colmex) y Carolina Agoff. En aquella investigación se formaron 10 grupos de discusión ( $N=112$ ) con mujeres que desempeñan algún trabajo extra doméstico y 8 entrevistas narrativas individuales en la Ciudad de México. El reclutamiento se llevó a cabo a través de una agencia a la que le proporcionamos los criterios de selección (tipo de trabajo, edad, número de hijos dependientes, escolaridad, estado civil etc.)
} 
presente estudio: 1) mujeres menores de 40 años y 2) mujeres mayores de $40 .^{17}$

Algunas de las preguntas utilizadas para detonar las conversaciones en los focus group fueron: ¿Qué significa descuidar la casa?, si tuvieran la posibilidad de que su marido las mantuviera ¿Sería una opción para todas?, ¿Cuál sería el trabajo ideal para ustedes? ¿Cuál es la ventaja de tener un negocio propio o de trabajar fuera de casa? y ¿Cómo se reparten el trabajo doméstico? Las interrogantes variaron en los diferentes grupos y se plantearon en momentos diversos, aunque su rasgo común es que con ellas se buscaba que las participantes cuestionaran los roles de género y reflexionaran sobre las normas y los morales al interior de sus grupos familiares.

Los datos se analizaron conforme a los principios de la teoría fundamentada (Glaser y Strauss 1967; Strauss y Corbin 1990). Los hallazgos que se presentan a continuación conforman el desarrollo de las categorías fundadas empíricamente y relacionadas con la pregunta que atañe a la transformación de la moralidad en las familias. Los testimonios constituyen una ilustración de las categorias descubiertas. Esta investigación se complementó con la revisión bibliográfica sobre cuestiones jurídicas y las reformas legislativas más recientes en materia familiar y de género. En términos de los objetivos de este artículo, se colocó un énfasis particular en la legislación aprobada en la Ciudad de México, siempre que estuviese vinculada de forma directa con el objeto de estudio.

\section{Resultados y discusión}

Un campo de batalla: la resistencia al control y la defensa del trabajo

La familia como institución generizada muestra conflictos fruto de la relación desigual de poder. Se identificaron varios "campos de batalla" en donde hay una pugna por establecer otros arreglos normativos de parte de las mujeres, dando cuenta así de su capacidad de agencia y resistencia frente a los viejos valores y expectativas de género.
El grupo de las mujeres jóvenes da testimonio de los conflictos con los maridos por trabajar fuera de la casa, donde el dinero que ella gana resulta para ellas un arma de negociación, como también de resistencia al control que ellos intentan imponer.

\begin{abstract}
Moderadora: ¿Y por qué será que a los hombres les molesta que uno gane más? (Hablan varias a la vez)

V: Pierden el control, por ejemplo yo no tengo que pedirle, '¿me das para mis cosas?', 'hijole, ya se me acabo el tinte', no, yo tengo mi dinero o no le digo '¿me compras esta blusa?', entonces no controla mi...

C: Tienes poder adquisitivo ¿no? cuando tú trabajas tienes poder adquisitivo y eso pues sí, lo que tu ganas en un día, a lo mejor lo que ellos ganan en un mes y eso te libera y ellos de cierta forma pues pierden el control ( $V$ y $L$ asienten con la cabeza) o sea es consecuencia de eso.

Moderadora: ¿Y han llegado a tener conflictos o broncas?

(Casi todas dicen "Sí" o asienten con la cabeza) Moderadora: ¿De qué tipo?

E: Del tipo de que 'ya no quiero que trabajes', pero como ya ven el ingreso que haces y ayudas a la economía pues ya.
\end{abstract}

M: Ah, porque cuando cobras si les gusta.

(Se rien varias) (Grupo de mujeres menores de 40 años)

Este intercambio grupal expresa el tipo de conflictos que ocasiona el que ella tenga un trabajo fuera del hogar y demuestra la tensión entre las viejas expectativas de rol de género en el caso de sus maridos y la defensa de nuevos valores y prácticas de ellas. La pérdida de control que experimentan los hombres porque las mujeres ya no dependen económicamente de ellos genera conflictos, pero ellas rescatan como balance la independencia que logran al tener su propio dinero (y no tener que pedirle y por tanto no depender de él), una sensación de autonomía que se vive como liberación de la dependencia y/o control.

Las mujeres más jóvenes dan cuenta de la resistencia y negociación por el ejercicio del control del marido, posibilitado sin duda por contextos 
sociales más permisivos; mientras que las mayores han dejado esa batalla atrás y han salido aparentemente vencedoras. Hay sin embargo una diferencia considerable en el lenguaje que utilizan ambos grupos para referirse a prácticas similares. En efecto, resulta muy interesante observar el uso del lenguaje que expresaba las expectativas de género tradicional, según las cuales el hombre provee y la mujer se ocupa de las tareas domésticas y cuidado de los hijos. Cuando ambos trabajan fuera de la casa, los viejos roles se experimentan como "ayuda" mutua, según la regla "Yo te ayudo a ganar dinero, tú me ayudas con el quehacer".

R: Yo nunca tengo un peso, yo nunca tengo una cuenta bancaria, no tengo nada porque toda mi vida que he trabajado le ayudo acá a la hija, a la otra hija, le ayudo a mi marido y le doy a mi mamá y no me siento mal por eso, al contrario estoy a gusto. l... yo en mi taxi y lo que vendo de Natura soy feliz. Me ayuda, si también me ayuda con el quehacer. Si, yo no tengo un quinto, pero para mi eso no es necesario porque él ahora lo estoy enseñando a que cumpla con los gastos de la casa porque él es el hombre, él quiere el título de ser el mandamás ahi, él quiere tomar la batuta cuando yo la tuve durante mucho tiempo, entonces que la tome pero completa, que pague renta... le está siendo muy dificil pero yo le ayudo económicamente (Grupo de mujeres mayores de 40 años).

B: Si, me dedico a eso porque al principio fue por mis hijos que eran muchos, para ayudarle a mi marido con el gasto. Ahorita ya lo hago porque ya me conocen y me hablan y es un dinero extra para mi (Grupo de mujeres mayores de 40 años).

$\mathrm{N}$ : Trabajar para ayudar a nuestra pareja ¿no? porque ahora ya es necesario, no es nada mas de que el hombre tenga que trabajar, si nosotros vemos que no alcanza o si alcanza todavia ayudar para que uno pueda salir mejor tanto para los hijos.

M: Mi opinión, mi ventaja es superación personal y familiar. Porque cuando uno sale a laborar en donde se pueda, ayuda uno a la familia económicamente y hace lo que le agrada a uno personalmente (Grupo de mujeres mayores de 40 años).

C: Mi mamá está conmigo, mi mamá a pesar de que ya es una persona mayor, tiene 78 años, mi mamá hace la comida todavia y me da y me dice: 'tú no te preocupes por la comida yo la hago tú nada más tráeme todo, dime que voy a hacer y lo hago y tú dedicate a lo que tienes que hacer de ayudarle a tu esposo y yo hago la comida yo recojo la cocina" (Grupo de mujeres mayores de 40 años).

G: Entonces por ejemplo él mete la ropa a lavar, cuando yo llego hasta la dobló, ya lavó los tras- tes, mantiene la casa limpia, yo de verdad que nada más para guisar, eso es lo que yo hago en la casa, porque él me ayuda en todo pero porque sabe que, o sea está consciente que la que lleva el dinero a la casa soy yo (Grupo de mujeres mayores de 40 años).

B: También mi esposo conmigo cuando yo tengo que salir y él está en casa me ayuda con los quehaceres que quedan pendientes para que yo no llegue a trabajar más (Grupo de mujeres mayores de 40 años).

Este uso aggiornado del término "ayuda" y la idea de que a ellos se les enseña (le estoy enseñando o reeducando como en el caso anterior) podría estar revelando que esta es la generación que verdaderamente es la primera en transitar el cambio de normas de convivencia, dándole a los viejos términos un nuevo significado. El idioma refleja elementos que remiten a estructuras ancestrales de dominación, pero los mismos términos adquieren nuevos significados. Es de destacar que las mujeres más jóvenes ya no hablan de ayuda o apoyo en ese sentido.

Se evidencia también que las mujeres confieren un peso central al hecho de que trabajan con respecto a la igualdad de derechos frente a sus esposos. Particular interés reviste lo expresado por dos participantes, en grupos diferentes:

$\mathrm{N}$ : Cuando no le parece algo que hice, es que no hiciste esto, esto y esto, 'Rey aqui también vives tú, vivimos los dos aqui, tenemos los dos los mismos derechos y los dos compartimos la misma hija, asi como trabajo yo, también trabajas tú' y pues no se me hace justo que nada más yo la casa. La verdad yo no pago ningún servicio, él paga todo, porque antes yo le ayudaba mucho... (Grupo de mujeres menores de 40 años).

Moderadora: ¿Algún caso distinto? Pero si se quieren comprar como decia M, algo para una, ¿piden permiso?, ¿preguntan?

(La mayoría dicen que no, otras observan o comen)

M: Ahora ya no. Lo que le digo yo a mi esposo ahorita ya tenemos derechos iguales, tanto tu puedes decidir como yo, ¿por qué?, porque igual aportamos los dos, no por el simple hecho de que tú des el gasto digas no esto no, no fijate que no, porque si a mi me gustaba pues yo me lo compro'.

Moderadora: ¿Y siempre fue asi o te costó trabajo?

M: No, pues si cuesta trabajo porque al principio uno no cuenta con eso, pero ya después pues de- 
pende de lo que uno tenga, como lo gane y cuanto gane (Grupo de mujeres mayores de 40 años, p. 8).

Con respecto a lo anterior quedaría por averiguar si el reconocimiento del valor económico del trabajo en el hogar y el cuidado de los hijos en el código civil de la Ciudad de México, ha tenido o tendrá alguna influencia sobre las opiniones de las mujeres, y si esto supondrá la resignificación de la valía que hasta ahora se ha asignado a las tareas de reproducción. Quizá cuando este significado jurídico permee en la mayoría de la sociedad, finalmente dejen de verse como una "ayuda" las tareas del hogar.

\section{Otro "campo de batalla": las tareas domésticas y el cuidado de los hijos}

Un "campo de batalla" más es el de la distribución de las tareas domésticas y el cuidado de los hijos en las mujeres más jóvenes. Aunque una pequeña porción de ellas sostiene que el ideal son los acuerdos consensuados y no los papeles adscriptos según el género, la mayoría se encuentra intentando que los hombres colaboren de manera equitativa.

Moderadora: ¿Y en las tareas del hogar hay reparto también?

(La mayoría niega con la cabeza, sólo C y M dicen "si")

$\mathrm{N}$ : Cuando él descansa, descansa, cuando yo descanso, ahora ponte a hacer todo lo que no hiciste en toda la semana, o sea una lavada al baño, al refrigeradora o sea, porque si tienes trabajo descuidas, y cuando él descansa es su descanso.

E: Yo cuando descanso, estar con los niños o haciendo tarea, o sea dedicando a los niños.

Moderadora: ¿Y no le dedican tampoco tiempo a los niños? los maridos.

(Muchas dicen que si)

Moderadora: ¿Qué cosas si ellos pueden hacer y qué cosas no pueden hacer?

E: Pues yo creo que pueden hacer todo, la cosa es que quieran (varias dicen "quieran" al mismo tiempo) porque no es gran ciencia lavar, nada más le echas y le prendes y ahi se lava (Grupo de mujeres menores de 40 años, p. 9).
De nuevo aparece la idea de que las tareas del hogar son de género neutral ("no es gran ciencia") y un tono irónico que refleja cierto malestar cuando se afirma que el descanso (esto es, cuando se llega a casa después del trabajo extra-doméstico) supone enfrentar la segunda jornada de trabajo. ahora en la casa. Según las participantes, la cuestión es que haya voluntad de parte de ellos para colaborar en la casa, no que lo sepan hacer. El otro grupo lo expresa del siguiente modo. Se espera que haya una distribución de tareas equitativa según el principio de lo que se debe hacer (ought) en término impersonales, ${ }^{18}$ no atado al género, lo que sugiere que no se trata de una imposición arbitraria por parte de ella.

R: Pero ya él mismo le está cayendo el veinte de cómo se deben de hacer las cosas en el momento que se deben de hacer y porque se tienen que hacer, no es mucho. Se ponen como si uno quiere obligarlos a hacer lo que tiene que hacer, no es lo que tiene que hacer, es lo que se debe de hacer porque en el momento se necesita. (Grupo de mujeres mayores de 40 años, p. 28)

Si bien es cierto que el debe ser (ought) de las tareas de la casa (expresado en el impersonal "se debe hacer") y el cuidado (las obligaciones) deben llevarse a cabo -no importa por quienen forma de una cooperación, las mujeres del siguiente testimonio se permiten además negociar la distribución de acuerdo según gustos y preferencias en la realización de las diferentes tareas:

M: Por ejemplo mi marido que hace el aseo, porque a mi no me gusta hacerlo, pero yo contribuyo a otras cosas, quizás yo hago ciertas que no le gusta a él, si yo tengo que ir a ver clientes y diseñar algo él se queda en casa, hace el aseo, o hace la comida pero porque a mi no me gusta. él tiene la obligación desde que nos casamos.

Moderadora: ¿Y cómo lograste eso?

W: Con un látigo.

M: Platicando, yo creo que llegando a cierta comunicación, a cierto plan de vida. Y así, yo odio lavar trastes, yo odio ir a las tortillas, y eso no hago, y pues 'a ver, ¿cómo le hacemos?', ¿no? (Fabiola se rie) Mmj, conversando y llegando a cierto plan.

18 Howell sostiene que los principios morales expresan simultáneamente una dinámica de relación intrínseca entre el "deber ser" y el "ser" (2007, 9). 
W: Yo lo tuve que acostumbrar a que me ayudara, porque era que no queria hacer nada, 'a ver papito, párate', primero le ayudaba yo, ya después se lo dejé. A veces lava la ropa, a veces lo trastes, o esta con su hija y ya que esté con mi hija ya digo yo, ya me puedo ir a hacer mis cosas.

C: No, yo creo que viene desde casa como dice, y aparte que sean empáticos contigo o sea que entiendan que este es un matrimonio funcional de dos personas, porque si hay maridos que te dicen 'ok, yo veo que estas cansada', o ni te lo dicen, ya lo vez trapeando, lo ves haciendo las cosas, claro, es un... igual cuando lo vez cansado pues tú lo haces, pero sí, viene de cómo te acostumbran de niño, de cómo estés educado, si, porque si estas educado... mis hermanos si son asi ellos no hacen nada, aunque estén en sus casas no hacen nada (Grupo de mujeres menores de 40 años, p. 10).

Estas mujeres jóvenes expresan el ideal y el valor de los acuerdos para una distribución equitativa de las tareas domésticas, dejando en evidencia una comprensión de la relación en términos de igualdad y mutualidad. Si bien observan que la crianza tradicional, según la cual las mujeres de la familia hacian todo. puede influir en que sus maridos no cooperen espontáneamente, también creen en el valor de la comunicación para lograr acuerdos y compartir equitativamente las tareas; afirman incluso que hay hombres que sienten empatía frente al cansancio de sus esposas. Más sorprendente aún resulta la afirmación de que no les gusta hacer determinadas cosas del hogar ("odio lavar", odio hacer el aseo o ir por las tortillas), cosa impensable poco tiempo atrás. ¿Qué contexto, qué circunstancias, qué cambios socioculturales hacen posible semejantes afirmaciones, hasta hace poco consideradas tabú?

En vistas de que hasta no hace mucho las mujeres estaban sujetas a su "oficio natural" de ama de casa, esposa y madre, con la dedicación exclusiva a la familia y al trabajo reproductivo en el espacio doméstico, es interesante comprobar que su identidad como mujeres ya no se ve comprometida en las citadas afirmaciones que deniegan el valor de esas tareas. Las viejas expectativas de género no resultaban sólo ideales de autorrealización, sino también constituian garantes del reconocimiento y valoración social, como también la base de su integración social.

R: Pero vaya, todavia aun como estamos que tenemos esos pensamientos de liberación, de liberación ¿de qué? si finalmente desde que nacemos hasta que morimos estamos esclavizadas a algo, a veces a nuestros propios sentimientos, necesidades, compromisos que nos hacemos con otras personas con los hijos, con los nietos, porque a mi quien me decia que terminábamos con los hijos cuando se casaban pues es una mentira porque simplemente y sencillamente llegan las nuera o el yerno y llegan los nietos...

E: Y llegan los problemas... (Grupo de mujeres mayores de 40 años, p. 10)

B: Me casé a los 15 años y siempre fue encerrada cuidando niños y hasta que yo vi que no alcanzaba el dinero dije 'no, yo tengo que salir', pero a mi ya me tenía frustrada el tener que estar en mi casa cuidando niños y con quehacer y al hacer una actividad que a mi me gusta y me deja algo de ganancia y a mi me alcanza para comprarme un gustito que yo tenga, pues eso si no lo dejaria de hacer por nada. (Grupo de mujeres mayores de 40 años, p. 20)

Esta libertad para expresar abiertamente disgusto por las tareas de la división sexual del trabajo tradicional se observa también en este caso de las mujeres mayores que caracterizan el cuidado de los hijos como una esclavitud. Hay un deseo de liberarse de la obligación del cuidado (primero los hijos, luego los nietos) que las ata de por vida a las necesidades de los otros. La posibilidad de hablar abiertamente de esto revela un cambio considerable acerca de la concepción de una "buena madre" que imperaba antes. Implica además una expresión de emociones, entendida como critical reasoning (Heller 1999; Nussbaum 2001) que refuerza la representación del cuidado de los menores: sentimiento de disgusto, frustración, encierro y esclavitud reflejan el poderoso deseo de liberación, ${ }^{19}$ de hacer lo que a una le gusta y planificar su propia vida.

\footnotetext{
19 Heller (1999) señala que los sentimientos morales cumplen una determinada función en el proceso de objetivación de los valores morales, esto es, lo que en una sociedad es considerado bueno o malo. En la misma línea, Nussbaum (2001) observa la relación estrecha entre emociones y normas sociales. De alli que cabe preguntarse de qué modo las variaciones en las normas comportan variaciones en las emociones (Nussbaum 1999, 6)
} 
Sin embargo estas aspiraciones colisionan con persistentes demandas de algunos familiares para que actúen de acuerdo a las viejas expectativas.

$\mathrm{N}$ : Yo no, asi como dice, estábamos acostumbradas en mi casa habia dos mujeres, hermanas y un varón y un papá de que siéntate 'ya llegue, usted sirvame refresco, tráeme la comida', (varias asienten con la cabeza), tráeme todo ¿no? tráeme todo, que yo lo hago cuando creces te vas a dar cuenta que eso no está bien, que eso no es propio, o sea va adquiriendo la conciencia de 'eso no quiero en mi vida', o sea de verdad...

M: Y porque te lo enseñan, yo creo que mucha de esas situaciones se vuelven acciones que no son correctas, pero las aprendes y las asumes como tal, porque ya te enseñan a ser complaciente, porque ya no ves ese lado.

N: Para eso estás, es un hábito, lo haces sin pensar.

M: Pero si lo tomas asi, o sea para mi punto de vista ya lo ves tan normal que es común y que dices bueno asi muchas veces digo no, yo no quiero eso para mi, 'a si papacito, ¿quieres un vaso? pues párate a la cocina mijo, tienes manos y pies y yo estoy igual de cansada que tú' (Grupo de mujeres menores de 40 años, p. 12)

Si estos reclamos no fuesen escuchados desde el hogar de origen, el derecho también puede operar como un desafortunado (pero muy diligente) recordatorio, de esos "roles tradicionales de género" para las mujeres. Aún en tiempos como el presente en los que prevalece la obligatoriedad para los jueces de dictar sentencias con perspectiva de género.

\section{Para concluir}

Tal como se expuso, la influencia reciproca constituye un rasgo esencial en la relación entre el derecho y la moralidad. Nuevos estándares de justicia social marcan el decurso de los cambios legislativosy de la transformación de la moralidad de las relaciones personales al promover nuevos valores y normas en la convivencia de las familias en la Ciudad de México. Esa pluralidad de los arreglos familiares en la capital federal nos deja entrever las tensiones que caracterizan a la dupla moral y derecho.

Lo analizado en los grupos focales expresa la vida familiar como una arena de disputa de moral para valores, normas de convivencia y prácticas, que deriva en una heurística para entender la transición hacia una nueva moralidad en las relaciones familiares en la Ciudad de México. Los conflictos ante las situaciones prácticas de estas mujeres expresan la resistencia al orden de género tradicional -el modelo patriarcal de familia- con sus reglas morales, y al que ellas contraponen nuevos valores y normas que apuntan a un ideal de la equidad.

Varias de las expresiones que dichas mujeres utilizaron para dar cuenta de las pugnas con sus maridos tienen una considerable densidad semántica, en donde los viejos términos se ven redefinidos y designan nuevas realidades. Así, mientras las mujeres de mayor edad todavía nombran su trabajo extradoméstico como "ayuda" en la organización familiar (y que alude al aporte femenino a la economía familiar del hombreproveedor), las más jóvenes se sitúan en un universo moral de conflictos, ya sin hacer uso de este vocablo. El discurso de éstas últimas sugiere una resistencia contra la noción de obligatoriedad encarnada en las viejas normas de género, en el ejercicio de control de sus maridos y en su falta de cooperación en las tareas domésticas y cuidado de los hijos asi como en la coerción que ejercen las familias para que ellas satisfagan las viejas expectativas de rol de género. Resulta interesante observar que hay una representación no atada al género sobre la responsabilidad de ganar el dinero y hacer las tareas que se vive como "gender-neutral", lo cual representa una enorme transformación respecto de los roles tradicionales y de la división sexual de tareas en el modelo funcionalista.

El viejo orden de género se confronta pues con una nueva moralidad de los intercambios de los grupos familiares, la cual se afirma en ideas como la de la responsabilidad compartida y del valor que se concede a los acuerdos.

\section{Referencias}

Agoff, Carolina. 2012. ¿Nuevos derechos hacen nuevas mujeres? El derecho a una vida libre de violencia como espacio de autoidentificación. In Cultura, sociedad y democracia en América Latina, editado por Klaus Bodemer, 187-202. Frankfurt: Vervuert. https://doi. org/10.31819/9783954870073-008 
Ariza, Marina y Orlandina de Oliveira, eds. 2004. Imágenes de la familia en el cambio de siglo. México: Unam.

Arriagada, Irma. 2009. La diversidad y desigualdad de las familias latinoamericanas. Revista Latinoamérica de Estudios de Familias 1: 9-21. https://doi.org/10.18356/68212e1f-es

Cuevas Hernández, y Ana Josefina. 2010. Jefas de familia sin pareja: estigma social y autopercepción. Estudios Sociológicos XXVIII, n. 84: 753-790.

Esteinou, Rosario. 2008. La familia nuclear en México: lecturas de su modernidad. Siglos XVI a XX. México: CIESAS-Miguel Ángel Porrúa. https://doi.org/10.22201/ fcpys.24484938e.2009.50.18732

Galicia Mendoza, Cynthia. 2016. Aportaciones del feminismo al derecho. In Lecturas criticas en investigación feminista, editado por Norma Blázquez Graf y Martha Patricia Castañeda Salgado,125-143. México: Unam.

Garcia, Brigida, y Orlandina de Oliveira. 2006. Las familias en el México metropolitano: visiones femeninas y masculinas. México: Colmex.

Gilligan, Carol. 1982. In a different voice. Psychological theory and women's development. Cambridge, MA: Harvard University Press.

Glaser, Barney, y Anselm Strauss. 1967. The discovery of grounded theory. Chicago: Aldine.

Held, Virginia. 1993. Feminist morality. Transforming culture, society and politics. Chicago y Londres: The University of Chicago Press. https://doi. org/10.1177/003231879504700124

Heller, Agnes. 1999. Teoría de los sentimientos. México: Fontamara.

Honneth, Axel y Beate Rössler. 2008. Von Person zu Person. Zur Moralität persönlicher Beziehungen. Frankfurt am Main: Suhrkamp.

Howell, Jude. 2007. Gender and civil society: time for cross-border dialogue. Gender, State \& Society 14, n.4: 415-436. https://doi.org/10.1093/sp/jxmo23

Inegi (Instituto Nacional de Estadística y Geografia). Encuesta Nacional de Ocupación y Empleo (Enoe), 2014.

Lerner, Susana, y Lucia Melgar, eds. 2010. Familias en el siglo XXI: realidades diversas y politicas públicas. México: Pueg-Colmex.

López, Maria de la Paz, y Vania Salles, eds. 2000. Familia, género y pobreza. México: GIMTRAP, Miguel Ángel Porrúa.

Macintyre, Alasdair. 1981. After virtue. A study in moral theory. Notre Dame: Notre Dame University Press. https://doi.org/10.1017/s0360966900022416

Marx Ferree, Myra. 2010. Filling the glass: gender perspectives on families. Journal of marriage and Family 72 : 420-439. https://doi.org/10.1111/j.1741-3737.2010.00711.x

Nussbaum, Martha. 1999. Sex and social justice. Nueva York: Oxford University Press.
Nussbaum, Martha. 2001. Upheavals of thought. The intelligence of emotions. Reino Unido: Cambridge University Press.

Oliveira, Orlandina de. 2000. Transformaciones socioeconómicas, familia y condición femenina. In Familia, género y pobreza, editado por Maria de la Paz López y Vania Salles. s. p. México: Miguel Ángel Porrúa.

Rabell Romero y Cecilia Andrea, eds. 2009. Tramas familiares en el México contemporáneo. Una perspectiva sociodemográfica. México: Instituto de Investigaciones Sociales-Colmex.

Rojas, Olga Lorena. 2012. Masculinidad y vida conyugal en México. Cambios y persistencias. Revista de Investigación y divulgación sobre los estudios de género 10. n. 2: 79-104.

Smart, Carol. 2000. La teoría feminista y el discurso jurídico. In El derecho en el género y el género en el derecho, editado por Haydée Birgin, 31-99. Buenos Aires: Biblos. https://doi.org/10.32719/26312484.2018.29.1

Solana Ruiz, José Luis. 1998. Recensión 05. Joan Bestard: parentesco y modernidad. Gazeta de Antropología 14: 10-13.

Strauss, Anselm, y Juliet Corbin. 1990. Basics of qualitative research: techniques and procedures for developing grounded theory. Thousand Oaks, CA: Sage. https://doi. org/10.4135/9781452230153

Szasz, Ivonne. 1994. La pobreza desde la perspectiva de género: estado del conocimiento. In Las mujeres en la pobreza, editado por GIMTRAP, 17-46. México: Colmex. https://doi.org/10.2307/j.ctv512sog.4

Torres Falcón, Marta. 2009. iViva la familia! Un panorama de la legislación vigente en México. Alteridades 19. n. 38: 41-54.

Weller, Wivian, y Nicole Pfaff, orgs. 2011. Metodologias da pesquisa qualitativa em educação: teoria e prática. Petrópolis: Editora Vozes.

Wollstonecraft, Mary. 2005. Vindicación de los derechos de la mujer, editado por Marta Lois González. Madrid: Ediciones Istmo. https://doi.org/10.12795/ph.2003.v17.io2.09

Young, Iris M. 1997. Intersecting voices: dilemmas of gender, political philosophy, and policy. NJ: Princeton University Press.

\section{María Carolina Agoff}

Investigadora titular del Centro Regional de Investigaciones Multidisciplinarias (Crim), Universidad Nacional Autónoma do México (Unam), en Cuernavaca, México.

\section{Claudia Esthela Espinoza Cid}

Doctora en Ciencias Sociales por el El Colegio de Sonora (Unison), en Sonora, México. 